\title{
A Matemática na formação de professores primários no Espírito Santo (1890-1908)
}

\author{
Mathematics in the training of primary \\ teachers in Espírito Santo (1890-1908)
}

Les Mathématiques dans la formation des enseignants du primaire dans le Espírito Santo (1890-1908)

\section{Moysés Gonçalves Siqueira Filho*}

\section{Resumo}

O artigo tem por objetivo apresentar reflexões acerca da formação matemática de professores no Espírito Santo no início do século XX. Nos primeiros anos da República, o estado buscava desenvolver-se sócio e economicamente por meio de investimentos na educação. Destaca a participação do professor paulista Carlos Alberto Gomes Cardim, como personagem importante no processo de reformulação do Ensino Capixaba na primeira década do século XX. Utilizamos

* MGSF: Doutor em Educação, e-mail: siqueira.moyses@gmail.com 
como fontes primárias Relatórios encaminhados ao governo pelas autoridades que respondiam pela Instrução Pública, Leis e Decretos referentes à educação nesse período. Ressalta as interferências das Reformas Educacionais na composição dos currículos e no Método de Ensino presente na formação de professores, que, em geral, acontecia nas Escolas Normais.

Palavras-chave: Formação de professores. Matemática. Escola Normal. Espírito Santo.

\section{Abstract}

The article aims to present reflections about the mathematical formation of teachers in the state of Espirito Santo at the beginning of the 20th century. In the first years of Republic, the state was pursuing social and economic development by investing in education. This paper highlights the participation of Carlos Alberto Gomes Cardim, a teacher from São Paulo, as an important figure in the process of reformulating Espirito Santo teaching in the first decade of the 20th century. We used as primary sources Reports sent to the government by authorities that were responsible for Public Instruction, Laws and Decrees concerning the education in that period. This work also highlights the interference of Educational Reforms in curricula composition and in the Teaching Method verified on teacher training that, in general, occurred in Normal Schools.

Keywords: Teacher training. Mathematics. Normal School. Espírito Santo.

\section{Résumé}

L'article vise à présenter des réflexions sur l'éducation mathématique des enseignants dans I'Espirito Santo au début du XXe siècle. Dans les premières années de la République, l'Etat a cherché à partenaire et se développer économiquement grâce à des investissements dans l'éducation. Faits saillants de la participation du Professeur Carlos Alberto Gomes Cardim né à São Paulo comme un personnage important dans le processus de remodelage de l'éducation " capixaba » dans la première décennie du XXe siècle. Nous avons utilisé comme sources primaires ont présenté des rapports aux autorités gouvernementales qui étaient responsables de l'éducation publique, les lois et décrets sur l'éducation dans cette période. Faits saillants de l'interférence des réformes de l'éducation dans la composition des programmes et des méthodes d'enseignement de cette formation des enseignants, qui ont généralement eu lieu dans les écoles normales.

Mots-clés: Formation des enseignants. Mathématiques. École normale. Espírito Santo. 


\section{Introdução}

A instrução popular tornou-se, em 1889, uma das bandeiras de luta dos republicanos. A partir de 1893, inicialmente no estado de São Paulo, e depois por todo o país, que as escolas isoladas foram substituídas pelos chamados Grupos Escolares. Souza (2006) afirma que essa mudança representou uma das mais importantes inovações educacionais ocorridas no Brasil. Políticos e educadores paulistas pretendiam modernizar a educação e elevar o país ao patamar dos países mais desenvolvidos.

Nesse ínterim, Benjamin Constant ${ }^{1}$ assumiu a posição de Ministro da Instrução no governo de Marechal Deodoro da Fonseca e, juntos, assinaram o Decreto n. 981, de 8 de novembro de 1890, o qual aprovava o Regulamento da Instrução Primária e Secundária em âmbito nacional (BRASIL, 1890).

Noqueserefereàformação deprofessores, Reis Filho(1995, p.43), no corrente ano, ao citar trechos do jornal O Estado de S. Paulo, destaca: "Ora, não serão os velhos mestres [...] que hão de desempenhar a nova missão... é fora de dúvida que a República precisa formar novos mestres”. Mas quem seriam esses "novos mestres"? Qual seu perfil?

Muito provavelmente, uma possível resposta a estas perguntas esteja no parágrafo inicial do artigo $1^{\circ}$ do referido Decreto: "Para exercer o magisterio particular bastará que o individuo prove que não soffreu condemnação judicial por crime infamante, que não foi punido com demissão [...]" (BRASIL, 1890, p. 1). Portanto, bastaria que a pessoa fosse "um cidadão de bem" para ser professor, com o que também constatamos a carência de professores nesse período, haja vista a omissão da exigência de qualquer capacitação dos profissionais. Possivelmente, a desvalorização da profissão que ainda vivenciamos no Brasil tenha vestígios desse passado.

1 Benjamin Constant Botelho de Magalhães nasceu em 18 de outubro de 1836, no município de Niterói. Seguiu carreira militar, se formou em bacharel em Ciências Físicas e Matemática em 1860 e foi professor de Matemática da Escola Militar. Faleceu em 22 de janeiro de 1891, no Rio de Janeiro (CARTOLANO, 1994). 
O Decreto n. 981, além de regulamentar a Instrução Primária e Secundária ${ }^{2}$ em âmbito nacional, impunha aos professores de escolas públicas primárias o estudo de Português, noções de literatura nacional e elementos de língua latina, francês, geografia e história, particularmente do Brasil, matemática elementar ${ }^{3}$, mecânica e astronomia, física e química, biologia, sociologia e moral, noções de agronomia, desenho, música, ginástica, caligrafia, trabalhos manuais (para homens), trabalhos de agulha (para mulheres), e, ainda, serem alunos ou graduados em Escolas Normais.

De acordo com Schaffrath (2008), o projeto dessas Instituições surgiu na Europa, no início do século XIX, no bojo das discussões sobre a substituição do ensino privado e religioso pela escola gratuita, laica e obrigatória e, nesse sentido, a preparação dos professores para o exercício do magistério ocorria enquanto ainda eram alunos das Escolas de Primeiras Letras. Nessas instituições era adotado o Método Lancaster ${ }^{4}$, no qual alguns alunos atuavam como monitores auxiliando o professor e, portanto, aprendendo a profissão, além de estudarem "[...] as quatro operações matemáticas e proporções; conhecimentos da língua nacional; elementos de Geografia e princípios de moral cristã" (SCHAFFRATH, 2008, p. 146). Esses últimos, acompanhados dos bons costumes, segundo Villela (2010), faziam parte das exigências para nelas ser admitido, e deveriam ser comprovadas por atestados passados por autoridades locais e, posteriormente, analisados pelo presidente da província.

Note-se que, diante do projeto ambicioso de impulsionar o Ensino Primário no Brasil, surgia uma demanda inerente às reformas

2 Adotaremos, nesse texto, o termo conforme era utilizado à época, isto é, Instrução Pública ao invés de Educação Pública, como denominamos atualmente.

3 Por ora, não temos detalhes da composição da disciplina matemática elementar, mas podemos presumir sua constituição com base nos saberes que, segundo o referido Decreto, deveriam ser ensinados na escola primária: contar e calcular; Aritmética prática até regra de três; Sistema métrico precedido do estudo da geometria prática; Álgebra elementar; Geometria e trigonometria.

4 No modelo Lancasteriano, os grupos de 100 eram subdivididos em grupos de 10 alunos que ficavam sob os cuidados de um aluno monitor. O mestre, acomodado em uma cadeira alta, supervisionava toda a turma, inclusive os monitores (SAVIANI, 2008). 
da Educação: a preocupação com a formação de professores. Segundo Valente (2011), Cursos Normais foram criados e instalados, em muitas províncias, como anexos nos Liceus Provinciais, de forma que o curso de formação de professores tornava-se muito semelhante ao secundário, diferenciado apenas pela criação de uma cadeira de Pedagogia.

Embora tenha sido comum a instalação das Escolas Normais em todo o território brasileiro, Tanuri (2000) sinaliza uma trajetória atribulada demarcada por processos contínuos de reformulação e extinção. Como exemplo, a primeira Escola Normal criada em 1835, em Niterói (seguida pela da Bahia em 1842), foi fechada em 1849, por Couto Ferraz, presidente da província do Rio de Janeiro, por considerá-la onerosa e ineficiente na formação de professores; porém, foi reaberta dez anos mais tarde, em 1859. Enquanto a Escola Normal esteve desativada, as pessoas habilitavam-se professores à medida em que atuavam como ajudantes do regente de classe, por meio da prática de ensino. Uma ideia semelhante ao que ocorria em anos anteriores, quando os professores aprendiam a profissão, como dissemos, nas Escolas de Primeiras Letras. Com essa regressão a métodos ultrapassados, percebemos a resistência dos governantes em investir na formação dos professores vinda de longa data.

Assim posto, nosso interesse se pautou em identificar a matemática presente no currículo dos normalistas no Espírito Santo no final do século XIX e início do século XX. Para tanto, optamos por trabalhar sob uma perspectiva histórica, a partir de uma série de documentos obtidos em diferentes espaços, em busca de elementos existentes na sua composição para compreender a intencionalidade e as condições em que foram produzidos.

\section{A Escola normal do Espírito Santo}

Inicialmente, segundo Coutinho (1993), o Curso Normal no Estado do Espírito Santo acontecia no Colégio Normal Nossa Senhora da Penha, criado a partir do Decreto $\mathrm{n}^{\circ} 674$ de 06 de dezembro de 1869, cuja finalidade era habilitar professores para o Ensino Primário. Esta 
instituição, situada na cidade de Vitória, capital do Estado, contava com duas escolas primárias anexas, que funcionavam como escolas de aplicação. Entretanto, de acordo com Ferreira (2002) e Lima (1908), a primeira Escola Normal do Espírito Santo foi fundada em 14 de julho de 1892, passando a ser denominada Escola Normal Dom Pedro II no ano de 1925, em homenagem ao centenário de nascimento do segundo imperador do Brasil. O imóvel onde funcionava a escola, adquirido por ação da Fazenda Provincial, destacava-se por sua arquitetura neoclássica (BARRETO, 2007). Faria Filho e Vidal (2000, p. 24) destacam que, intencionalmente, as edificações escolares eram construídas visando a monumentalidade, "[...] valorizando uma simbologia estética, cultural e ideológica constituída pelas luzes da República”. A seguir, uma fotografia da Escola Normal D. Pedro II:

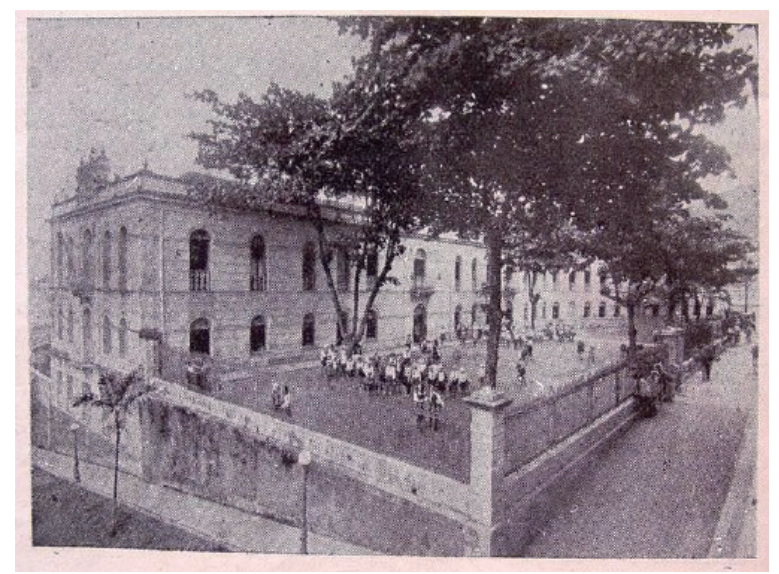

Figura 1 - Escola Normal D. Pedro II em 1930.

Fonte: Barreto (2007)

Contudo, a Escola Normal do Espírito Santo foi desativada em 1898, sendo reestabelecida no quatriênio seguinte, coincidentemente, no governo de José de Mello Carvalho Moniz Freire, reeleito para o período 1900 a 1904. 
Pontuamos em linhas atrás, que os princípios de moral cristã e bons costumes configuravam-se como exigências àqueles os quais quisessem ser admitidos nas Escolas Normais; reiteramos, agora, que tais atributos eram ainda mais severos com relação à mulher, atingindo, inclusive, sua vida privada. Nesse sentido, Barreto (2005, p. 4) afirma que as normalistas capixabas carregavam consigo alguns estereótipos característicos de submissão, aparentando ser "amáveis e dóceis". Ampliaremos essa questão, considerando a distinção entre os gêneros, presente nos currículos da Escola Normal do Espírito Santo, criada por meio do Decreto $\mathrm{n}^{\circ} 2$, de 4 de junho de 1892, no governo de Moniz Freire (1892-1896).

A reorganização do ensino primário iria diferenciar a duração do curso normal, sendo de cinco anos para os homens e de quatro para as mulheres, bem como a composição do currículo que, em relação à Matemática, fora composto pelos seguintes conteúdos:

\begin{tabular}{c|c|c}
\hline Seção Masculina & 2o ano & 3o ano \\
\hline & $\begin{array}{c}\text { Matemáticas Fundamentais: } \\
\text { Aritmética; Álgebra; } \\
\text { Geometria; } \\
\end{array}$ & $\begin{array}{c}\text { Matemáticas Fundamentais: } \\
\text { Aritmética; Álgebra; } \\
\text { Geometria; } \\
\text { Geral e Celeste. }\end{array}$ \\
\hline Seção Feminina & 3o ano & $\begin{array}{c}\text { Noções gerais de Mecânica } \\
\text { Geral e Celeste. }\end{array}$ \\
\hline & Aritmética & 40 ano \\
\hline
\end{tabular}

Quadro 1 - Conteúdos de Matemática previstos para a Escola Normal em 1892 Fonte: FERREIRA, 2002.

Além da limitação dada às Matemáticas, as disciplinas Física, Química e Biologia não figuravam no currículo da seção feminina. Entretanto, com relação ao curso primário, as diferenças entre os currículos, segundo o sexo, são mais amenas. Um único programa é apresentado, porém com a seguinte instrução: “Art. 27 - As escolas do sexo feminino professarão o mesmo ensino das do outro sexo, consultadas apenas as aptidões especiaes da mulher e seu destino social" (ESPÍRITO SANTO, 1892). Sobre esse aspecto Almeida (2006) comenta a relevância 
de ao longo dos séculos XVIII e XIX a finalidade da educação para as meninas era prepará-las para o serviço doméstico e o cuidado com o marido e com os filhos. Possivelmente esse era o "destino social" a que o artigo 27 se referia. Dessa forma, se dava preferência ao estudo de disciplinas como Trabalhos Manuais e Prendas Domésticas em detrimento ao da Aritmética ou Gramática. A autora ressalta que esses ideais permaneceriam por um longo tempo durante décadas do século XX.

Relevamos, ainda, haver no Decreto $\mathrm{n}^{\circ} 2$, em seu artigo 26, tácitas orientações dirigidas ao professorado, assim prescritas:

O professor deverá tornar o ensino tão pratico quanto possivel, procurando sempre fazer conhecido o objecto e suas qualidades, antes de formular qualquer versão abstracta, prescindindo de perturbar com as regras o processo de apreciação natural dos phenomenos, usando de linguagem clara, precisa e despretenciosa, e preferindo sempre a sua prelecção oral aos compêndios (ESPÍRITO SANTO, 1892, p. 1).

Em seu texto, podemos também identificar termos como "intuição inicial", "partindo sempre do empirico para o abstracto" e "preferindo sempre a intuição à regra", os quais indiciam a presença do processo de ensino intuitivo, consolidada pela Reforma da Instrução Pública paulista em 1890 (SOUZA, 1998). Para Oliveira (2015), a sistematização do Método Intuitivo pode ser resumida como experiências do sentido, levando a criança a fazer uso destes de modo que a aquisição do conhecimento seria mediada por sua própria curiosidade.

De acordo com Leme da Silva (2015), a divulgação do Método Intuitivo, o qual considera a aprendizagem da criança a partir da observação das coisas, era feita, no estado de São Paulo, por meio da revista pedagógica A Eschola Publica, cuja conclusão de uma de suas edições apresenta os aforismos de Pestalozzi como a base do ensino intuitivo. Dentre eles, destacamos:

III - Começae pelos sentidos e nunca ensineis a um menino o que elle puder descobrir por si. IV - Reduzi cada assumpto a seus elementos. Uma difficuldade de cada vez é bastante para uma criança. [...] 
VIII - Procedei do conhecido para o desconhecido; do particular para o geral; do concreto para o abstracto; do mais simples para o mais complicado (A ESCHOLA PUBLICA, 1895, p. 357-358).

Como se vê, São Paulo tornou-se referência para os outros estados brasileiros, de forma que os professores paulistas viajavam para as várias regiões do país para divulgar as ações educacionais empreendidas na Reforma. De acordo com Valente (2011, p. 82), essas ações: “[...] incluem elementos para além da formação dada pelas matérias das escolas complementares ${ }^{5}$. Buscase interferir nas práticas pedagógicas. Evidencia-se a ênfase na formação profissional [...]. Urge modificar o ensino nas escolas paulistas".

Retomando o programa de ensino da Escola Normal no Espírito Santo, nos adiantemos até o ano de 1908, quando o Decreto no 109 de 4 de julho estabelece o regulamento das Escolas Normal e Modelo, determinando um currículo bem diferente daquele definido em 1892 (ESPIRITO SANTO, 1908). Os conteúdos de Matemática foram reduzidos e tornaram-se idênticos para ambos os sexos, como podemos verificar:

\begin{tabular}{c|c|c}
\hline Seção Masculina & 20 ano & 3 ano \\
\hline & $\begin{array}{c}\text { Matemáticas Fundamentais: } \\
\text { Aritmética; Álgebra; } \\
\text { Geometria; } \\
\text { Noções gerais de Mecânica } \\
\text { Geral e Celeste. }\end{array}$ & $\begin{array}{c}\text { Matemáticas Fundamentais: } \\
\text { Aritmética; Álgebra; } \\
\text { Geometria; } \\
\text { Seção Femines gerais de Mecânica } \\
\text { Geral e Celeste. }\end{array}$ \\
\hline & 3 ano & 4 ano \\
\hline & Aritmética & Geometrias \\
\hline
\end{tabular}

Quadro 2 - Conteúdos Matemáticos estudados na Escola Normal em 1908 Fonte: Decreto n. 109 de 4 de julho de 1908, p. 1.

5 As escolas complementares foram criadas inicialmente em São Paulo no ano de 1894, para diplomar professores, em função do baixo número de formandos da Escola Normal (VALENTE, 2011). Segundo Souza (1998), a formação nessas instituições era precária se comparada às Escolas Normais. Com características como um único professor polivalente para ministrar todas as matérias correspondentes a cada ano do curso, elas representavam um custo menor para o governo. As Escolas complementares formaram um número maior de professores do que as Escolas Normais, chamados de complementaristas. 
Além disso, o curso normal passou a ter a mesma duração em anos para as seções Masculina e Feminina. Nesse sentido, o currículo para a seção feminina teve um aumento significativo de matérias quando comparado ao de 1892, o qual estava muito aquém do que os homens estudavam.

Em relação aos métodos de ensino, os relatórios elaborados por pessoas que ocupavam cargos de chefia na Secretaria de Instrução Pública do Estado e encaminhados ao governo do Espírito Santo, nesta primeira década do século XX, explicitam os termos Método Intuitivo Analítico, Método Analítico e Processo intuitivo, de forma que não nos tornou clara a distinção entre os métodos e processos.

Contudo, sabemos que o Método Analítico passou a ser divulgado tanto pelos educadores brasileiros, conforme descreve Valente (2011), quanto pelo diretor da Escola Normal do Estado de São Paulo, Oscar Thompson, que assume posição em seu favor ao retornar de uma viagem feita aos Estados Unidos, em 1904. Não obstante, o Método Intuitivo continuava presente nos discursos educacionais. Mortatti (2000) sinaliza os métodos intuitivo e analítico os quais passaram a ser divulgados no Brasil, inicialmente, para a alfabetização, estendendo-se depois para todas as áreas do ensino.

Fora também em 1908 que a Reforma Gomes Cardim ocorreu no Espírito Santo. De acordo com Siqueira Filho (2014), o professor paulista Carlos Alberto Gomes Cardim chegou ao Estado em 29 de junho daquele ano, sendo posteriormente nomeado diretor da Escola Normal, tendo como missão reformular a educação espírito-santense. Não obstante, o autor conclui que a Reforma Gomes Cardim funcionou mais como um mecanismo de controle, impondo aos professores a metodologia de ensino a qual deveria ser utilizada.

Cardim (1909) defendia, veementemente, o Método Analítico para o ensino de todas as disciplinas e, com o intuito de expor provas convincentes de sua funcionalidade, apresentava os números de aprovações dos alunos na Escola Modelo. Para ele (1909, p. 5), “o papel do educador consciente é procurar o methodo de ensino que a evolução da pedagogia 
apontar. Dar liberdade aos professores seria implantar a confusão no ensino, por isso que cada cerebro é um capitolio e cada cabeça uma sentença".

Dentre as várias medidas por ele tomadas, em território capixaba, destacamos a realização do Congresso Pedagógico Espírito-Santense em 1909. Muitos professores foram convidados para discursarem no Congresso, entre eles Joaquim Fernandes de Andrade e Silva, proferindo palestra acerca da Matemática (CARDIM, 1909). Em seu discurso estabeleceu o desdobramento da disciplina em Aritmética e Geometria, considerando a primeira muito simples e a segunda com uma complexidade crescente. Demonstrou a facilidade que representa o Método Indutivo no estudo da Matemática, citando Kepler que, por meio da indução, chegou às suas leis. Citou também o Método Dedutivo mencionando Picard e Newton. Posteriormente, levantou as seguintes questões: "Terá a mathematica tão grande valor deductivo que compense o esforço de transformar o methodo que é próprio, para adaptal-o ao ensino infantil? Terá a mathematica valor educativo? Prestar-se-á ao desenvolvimento da natureza da creança?" (CARDIM, 1909, p. 46).

Em busca de argumentos para respostas convincentes, Andrade e Silva (1909) apontam a Matemática como sendo a melhor ginástica mental, parafraseando Sócrates, ao afirmar que a ciência é virtude, e que a Matemática exercia influência sobre o caráter do indivíduo, busca na história sua apreciação pela Geometria, desde os tempos da antiguidade, como também comenta a utilização da matemática na idade média, na época dos gregos e romanos, e discute acerca do complicado ensino mnemônico e do moderno ensino intuitivo.

Com base na análise em outros discursos proferidos no Congresso Pedagógico, percebemos, em geral, a preocupação com a divulgação dos Métodos de Ensino e com os resultados da Reforma no Ensino. Tal reforma, cujos princípios a ela imputados, se estenderiam para a década seguinte iniciou-se no governo anterior, de Moniz Freire, mas ganhou força com a chegada de Gomes Cardim ao governo de Jeronimo Monteiro. 


\section{Considerações finais}

Vimos que, com a Proclamação da República, os estados brasileiros aspiravam por um modelo educacional o qual representasse eficiência e progresso para a sociedade. Diante desse ideal, a Reforma iniciada em São Paulo, em 1890, foi propagada para o restante do país como sinônimo de modernidade na organização do sistema de ensino.

Posterior à criação da primeira Escola Normal do Espírito Santo, as outras instituições desse modelo foram sendo implantadas, lentamente, em seu território. Ferreira (2002) afirma a existência de seis Escolas normais, em terras capixabas, de 1929 até 1935. Dessas , apenas uma era mantida pelo Estado e três estavam localizadas na capital, sendo provável que as demais fossem fomentadas pela iniciativa privada. A mesma lentidão na implantação de Escolas Normais também pode ser percebida em relação aos grupos escolares. De acordo com os relatórios de governo, entre 1908 e 1929 foram criados quatro grupos escolares, enquanto em São Paulo, por exemplo, Costa (2010) revela que no período de 1890 a 1920 foram construídos mais de 130 grupos escolares.

De fato, no Espírito Santo a atmosfera de mudança só ocorrerá em 1908, com a chegada do professor paulista Gomes Cardim, cuja função foi remodelar o ensino público no âmbito estadual. Dessa forma, leis e decretos criam o primeiro grupo escolar na sua capital, Vitória, e o nomeiam diretor da Escola Normal, a qual sofre alterações em seus horários e programas de ensino.

Fica claro que o Espírito Santo, assim como outros estados, busca referências em São Paulo para a "modernização" da Instrução Pública. Como, por exemplo, a imposição do Método Analítico ao professorado capixaba, não apenas na alfabetização, mas também no ensino de outras disciplinas, inclusive a Matemática, em substituição ao Método Sintético, representante da escola tradicional e racionalista. Embora as propostas de Gomes Cardim tenham surtido avanços para a educação no Espírito Santo, percebemos que o Estado caminhou, vagarosamente, em prol de melhorias no ensino, após o retorno do professor paulista à cidade de São Paulo. 


\section{Referências}

ALMEIDA, J. S. de. Mulheres na Educação: missão, vocação e destino? A feminização do magistério ao longo do século XX. In: SAVIANI, Demerval [et al.]. O legado educacional do século XX no Brasil. 2 ed. Campinas: Autores Associados, 2006. p. 58-107.

ANDRADE e SILVA, J. F. O Ensino de Arithmetica na escola primaria. In: CARDIM, C. A. G. Acta apresentada ao Exmo. Snr. Dr. Jeronymo de Souza Monteiro. Presidente do Estado do Espírito Santo pelo Sr. Inspector Geral do Ensino Carlos A. Gomes Cardim na sessão de encerramento dos trabalhos do Congresso Pedagógico Espírito-Santense. Victória: Imprensa Oficial, 1909. Acervo: APEES. Disponível em <http://repositorio.ufsc.br/handle/123456789/115842>. Acesso em: 23 jan. 2015.

BARRETO, S. M.da C. A Escola Normal D. Pedro II e a normalista capixaba na memória cultural da Primeira República: década de 1920. In: Simpósio Nacional de História, 23, 2005, Londrina. Anais... Disponível em: <http://anpuh.org/anais/ wp-content/uploads/mp/pdf/ANPUH.S23.0960.pdf >. Acesso em: 20 fev. 2015.

BARRETO, S. M. C. A Escola Normal D. Pedro II e a normalista capixaba nos anos 1920. Revista Agora. Vitória, n. 6, p. 1-16, 2007. Disponível em: <http://periodicos.ufes.br/agora/article/viewFile/1916/1428>. Acesso em: 20 fev. 2015.

BRASIL. Câmara dos Deputados. Decreto $n^{\circ}$ 981, de 8 novembro de 1890. Aprova o regulamento da Instrução Primaria e Secundaria do Districto Federal. Disponível em: <http://www2.camara.leg.br/legin/fed/decret/1824-1899/decreto-981-8-novembro-1890-515376-publicacaooriginal-1-pe.html>. Acesso em: 15 mai. 2015.

CARDIM, C. A. G. Acta apresentada ao Exmo. Snr. Dr. Jeronymo de Souza Monteiro. Presidente do Estado do Espírito Santo pelo Sr. Inspector Geral do Ensino Carlos A. Gomes Cardim na sessão de encerramento dos trabalhos do Congresso Pedagógico Espírito-Santense. Imprensa Oficial, Victória: Acerco APEES, 1909. Disponível em <http://repositorio.ufsc.br/handle/123456789/115842>. Acesso em: 23 jan. 2015. 
CARTOLANO, M. T. P. Benjamin Constant e a Instrução Pública no Início da República. 288 f. Tese (Doutorado em Educação) Faculdade de Educação, Universidade Estadual de Campinas, Campinas, 1994.

COSTA, D. A. da. A Aritmética escolar no ensino primário brasileiro: 1890-1946. Tese (Doutorado em Educação Matemática) - Pontifícia Universidade Católica de São Paulo, São Paulo, 2010.

COUTINHO, J. M. Uma História da Educação no Espírito Santo. Vitória: Departamento Estadual de Cultura/ Secretaria de produção e Divisão Cultural UFES, 1993.

ESPÍRITO SANTO (Estado). Decreto n ${ }^{\circ} 2$, de 4 de junho de 1892. Dá regulamento ao serviço de instrucção publica. O Estado do Espírito Santo, Vitória, ano XI, n. 2765, 17 jun. de 1892. Parte Official, p. 1. Disponível em: <http://bndigital. bn.br/hemeroteca-digital/>. Acesso em: 22 jun. 2015.

ESPÍRITO SANTO (Estado). Decreto no 109, 4 jul. 1908. Dá regulamento ás Escolas Normal e Modelo Annexa do Estado do Espírito Santo. Diario da Manhã. Vitória, ano I, n. 254, 8 jul. 1908. Actos Officiaes, p.1. Disponível em: <https:// repositorio.ufsc.br/handle/123456789/122510>. Acesso em: 15 mai. 2015.

FARIA FILHO, L. M. de; VIDAL, D. G. Os tempos e os espaços escolares no processo de institucionalização da escola primária no Brasil. Revista Brasileira de Educação, Rio de Janeiro, n. 14, p. 19-34, Mai./Jun./Jul./Ago. 2000. Disponível em: 〈http://www.scielo.br/pdf/rbedu/n14/n14a03>. Acesso em: 21 fev. 2015.

FERREIRA, L. V. A Educação Matemática nas Escolas Normais do Espírito Santo: Um Resgate Histórico de Formação de Professores. 2002. 155f. Dissertação (Mestrado em Educação). Programa de Pós-Graduação em Educação, Universidade Federal do Espírito Santo, Vitória, 2002.

LEME DA SILVA, M. C. Revista A Eschola Publica (1896-1897): saberes geométricos e o método analítico. In: Seminário temático saberes elementares matemáticos do ensino primário (1890 - 1971), 12, 2015, Curitiba. Anais eletrônicos ... Disponível em: <http://www2.td.utfpr.edu.br/seminario_tematico/artigos/55. pdf $>$. Acesso em: 20 jun. 2015. 
LIMA, H. A. C. Relatório apresentado ao Exmo. Snr. Dr. Jeronymo de Souza Monteiro. Presidente do Estado do Espírito Santo pelo Director da Instrucção Dr. Henrique A. Cerqueira Lima em 13 de agosto de 1908. Vitória: Imprensa Estadual, 1908. Acervo: APEES.

MORTATTI, M. do R. L. Os sentidos da alfabetização: São Paulo/1876-1994. $3^{\text {a }}$ reimpressão. São Paulo: Editora UNESP, 2000.

OLIVEIRA, M. A. Pestalozzi, o método intuitivo e os saberes elementares aritméticos. In: VALENTE, Wagner Rodrigues (Org.). Método. Cadernos de Trabalho, v. 4. São Paulo: Editora Livraria da Física, 2015.

REIS FILHO, C. A educação e a ilusão liberal. 2. ed. Campinas: Autores Associados, 1995.

SÃO PAULO (Estado). A Eschola Publica - Ensaio de Pedagogia Prática. Typographia Paulista. 1895. Disponível em: <http://www.arquivoestado.sp.gov. br/educacao/publicacoes.php >. Acesso em: 01 jun. 2015.

SAVIANI, D. Histórias das ideias pedagógicas no Brasil. 2 ed. Campinas: Autores Associados, 2008.

SCHAFFRATH, M. dos A. S. Escola Normal: O projeto das elites brasileiras para a formação de professores. In: Encontro Interdisciplinar de Pesquisa em Artes, 1., 2008, Curitiba. Anais... Disponível em <http://www.fap.pr.gov.br/arquivos/File/ Arquivos2009/Extensao/I_encontro_inter_artea/20_Marlete_Schaffrath.pdf >. Acesso em: 02 fev. 2015.

SIQUEIRA FILHO, M. G. A passagem de Gomes Cardim pelo Espírito Santo e a Incorporação de suas Intencionalidades: os programas de ensino primário de Aritmética, Desenho e Geometria nos entremeios das décadas de 1908 a 1928. In: COSTA, D. A. da; VALENTE, W. R. (Orgs.). Saberes Matemáticos no curso primário: o que, como e por que ensinar? Editora Livraria da Física: São Paulo, 2014. SOUZA, R. de F. Templos de civilização: implantação da escola primária graduada no Estado de São Paulo (1890-1910). São Paulo: Fundação Editora UNESP, 1998. 
SOUZA, R. de F. Espaço da educação e da civilização: origens dos grupos escolares no Brasil. In: SAVIANI Demerval [et al.]. O legado educacional do século XIX. 2 ed. Campinas: Autores Associados, 2006. p. 33-84.

TANURI, L. M. História da formação de professores. Revista Brasileira de Educação, Rio de Janeiro, n. 14, p. 61-193, Mai./jun./jul./ago. 2000.

VALENTE, W. R. A matemática na formação do professor do ensino primário: São Paulo, 1875-1930. São Paulo: Annablume, 2011.

VILLELA, H. de O. S. O mestre-escola e a professora. In: LOPES, Eliane Marta Teixeira; FARIA FILHO, Luciano Mendes; VEIGA, Cynthia Greive (Org.). 500 anos de Educação no Brasil. Belo Horizonte: Autêntica, 2010.

Recebido: 20/04/2016

Received: 04/20/2016

Aprovado: 17/06/2016 Approved: 06/17/2016 